\title{
Insight into the reaction mechanism of lipoyl synthase: a QM/MM study
}

\author{
Geng Dong ${ }^{1} \cdot$ Lili Cao $^{1} \cdot$ Ulf Ryde $^{1}$
}

Received: 23 October 2017 / Accepted: 28 November 2017 / Published online: 4 December 2017

(c) The Author(s) 2017. This article is an open access publication

\begin{abstract}
Lipoyl synthase (LipA) catalyses the final step of the biosynthesis of the lipoyl cofactor by insertion of two sulfur atoms at the C6 and C8 atoms of the protein-bound octanoyl substrate. In this reaction, two [4Fe4S] clusters and two molecules of $S$-adenosyl-L-methionine are used. One of the two FeS clusters is responsible for the generation of a powerful oxidant, the $5^{\prime}$-deoxyadenosyl radical $\left(5^{\prime}-\mathrm{dA}^{\bullet}\right)$. The other (the auxiliary cluster) is the source of both sulfur atoms that are inserted into the substrate. In this paper, the spin state of the FeS clusters and the reaction mechanism is investigated by the combined quantum mechanical and molecular mechanics approach. The calculations show that the ground state of the two FeS clusters, both in the $[4 \mathrm{Fe} 4 \mathrm{~S}]^{2+}$ oxidation state, is a singlet state with antiferromagnetically coupled high-spin Fe ions and that there is quite a large variation of the energies of the various broken-symmetry states, up to $40 \mathrm{~kJ} / \mathrm{mol}$. For the two $\mathrm{S}$-insertion reactions, the highest energy barrier is found for the hydrogen-atom abstraction from the octanoyl substrate by $5^{\prime}$-dA ${ }^{\bullet}$. The formation of $5^{\prime}-\mathrm{dA}^{\bullet}$ is very facile for LipA, with an energy barrier of $6 \mathrm{~kJ} / \mathrm{mol}$ for the first S-insertion reaction and without any barrier for the second S-insertion reaction. In addition, the first $\mathrm{S}$ ion attack on the C6 radical of octanoyl was found to take place directly by the transfer of the $\mathrm{H} 6$ from the substrate to $5^{\prime}-\mathrm{dA}{ }^{\bullet}$, whereas for the second S-insertion reaction, a C8 radical intermediate was formed with a rate-limiting barrier of $71 \mathrm{~kJ} / \mathrm{mol}$.
\end{abstract}

Keywords Lipoyl synthase $\cdot$ FeS cluster $\cdot$ Spin state $\cdot$ Reaction mechanism $\cdot$ QM/MM $\cdot$ Density functional theory

\section{Introduction}

Lipoic acid is a sulfur-containing cofactor that is essential for living organisms. It is employed in acyl-transfer reactions in several enzymes, including the pyruvate and $\alpha$-ketoglutarate dehydrogenases in the citric acid cycle [1]. Lipoyl synthase (LipA) is a metalloenzyme that catalyses the final step in the biosynthesis of this cofactor by the insertion of two sulfur atoms at the $\mathrm{C} 6$ and $\mathrm{C} 8$ atoms of the octanoyl substrate, attached to the lipoyl carrier protein (Scheme 1) [2-5]. LipA belongs to the $S$-adenosyl-L-methionine (AdoMet) radical enzyme superfamily, which uses a [4Fe4S] cluster (termed

Electronic supplementary material The online version of this article (https://doi.org/10.1007/s00775-017-1522-8) contains supplementary material, which is available to authorized users.

Geng Dong

Geng.Dong@teokem.lu.se

1 Department of Theoretical Chemistry, Chemical Centre, Lund University, P.O. Box 124, 22100 Lund, Sweden the main cluster in this paper) to reductively cleave the $\mathrm{C}_{5}{ }^{\prime}-\mathrm{S}$ bond of AdoMet, generating L-methionine and a 5'-deoxyadenosyl radical $\left(5^{\prime}-\mathrm{dA}^{\bullet}\right)$, which is a powerful oxidant and can be used to abstract a hydrogen atom from other molecules [6-9]. During the S-insertion reaction, two molecules of AdoMet are required (one for each sulfur insertion) to produce the lipoyl product [4]. An additional [4Fe4S] cluster (termed auxiliary FeS cluster) is also needed in the reaction, and it has recently been shown that it is the source of the inserted sulfur atoms $[10,11]$.

Crystallographic studies have shown that the two [4Fe4S] clusters are located in the active site of LipA [11, 12]. In the resting state (without octanoyl substrate and AdoMet binding to active site), the auxiliary [4Fe4S] cluster is bound to the protein with one Ser and three Cys residues, whereas three Cys resides and one solvent molecule coordinate to the other cluster. In the reactive state (when AdoMet and octanoyl groups bind to active site), the solvent ligand is replaced by the AdoMet group. During the first S-insertion reaction, the Ser residue dissociates from the auxiliary $\mathrm{FeS}$ cluster and one $\mathrm{Fe}$ ion is lost, whereas one of the sulfide ions 
Scheme 1 The sulfur-insertion reaction catalysed by LipA to form the lipoyl cofactor
Octanoyl-lipoyl carrier protein (LCP)

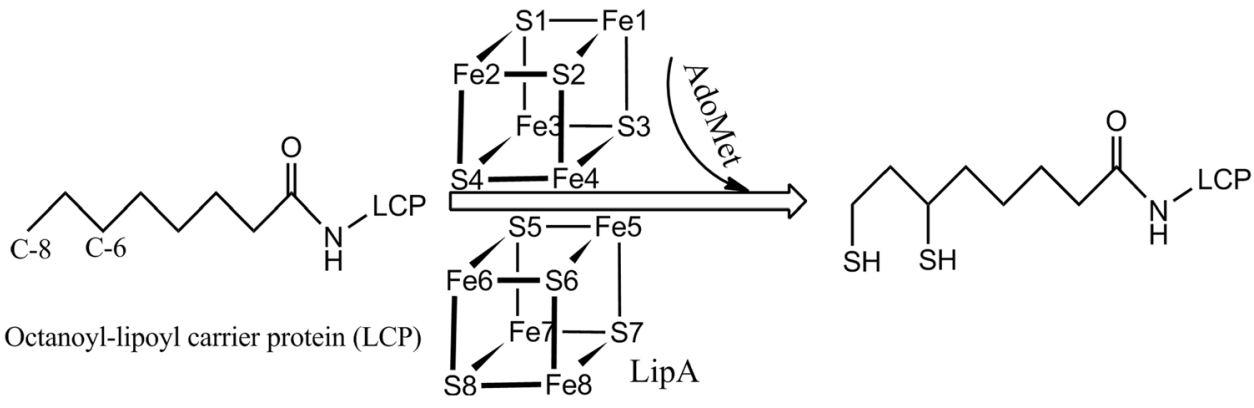

is inserted into the substrate. This may facilitate the second S-insertion reaction [11-13].

[4Fe4S] clusters are versatile cofactors in enzymes, playing important roles in biological electron transfer, biosynthetic reactions, as iron sensors and as the sulfur source in biological radical reactions [14-16]. To understand the structure-function relationship of [4Fe $4 \mathrm{~S}]$ cluster, many studies have been performed, both experimental and theoretical [17-33]. Broken-symmetry density functional theory (BS-DFT) calculations of the $[4 \mathrm{Fe} 4 \mathrm{~S}]^{2+}$ cluster (i.e., formally with two $\mathrm{Fe}^{2+}$, two $\mathrm{Fe}^{3+}$, and four $\mathrm{S}^{2-}$ ions) have shown that it consists of two high-spin ferromagnetically coupled $[2 \mathrm{Fe} 2 \mathrm{~S}]^{+}(S=9 / 2)$ subclusters, which together couple antiferromagnetically to the singlet state $(S=0)$ [24]. In each $[2 \mathrm{Fe} 2 \mathrm{~S}]^{+}$subcluster, the redox state of the two $\mathrm{Fe}$ ions is identical $\left(\mathrm{Fe}^{2.5+}\right)$. In addition, a recent $\mathrm{S} \mathrm{K}$-edge X-ray absorption spectroscopy study of [4Fe $4 \mathrm{~S}]$ clusters bound to AdoMet in pyruvate formate-lyase activating enzyme has suggested that there is a back-bonding interaction between the [4Fe4S] cluster and the $\mathrm{C}-\mathrm{S} \sigma^{*}$ orbital of AdoMet [22]. This is supported by DFT calculations, which indicate that such an interaction facilitates the electron transfer between the FeS cluster and AdoMet.
A reaction mechanism of LipA has been proposed based on the crystal structures (Scheme 2) [11, 12]. The redox states of the two FeS clusters in the resting state are both $[4 \mathrm{Fe} 4 \mathrm{~S}]^{2+}$. The reaction starts with the binding of AdoMet and octanoyl substrate to the active site, the former coordinating directly to the main $\mathrm{FeS}$ cluster by replacing the water ligand. During this process, Ser292 is protonated and dissociates from the auxiliary FeS cluster. Next, the main FeS cluster is reduced by one electron, giving the $[4 \mathrm{Fe} 4 \mathrm{~S}]^{+}-$AdoMet state. This triggers the cleavage of the $\mathrm{C}_{5}{ }^{\prime}-\mathrm{S}$ bond in AdoMet to generate $[4 \mathrm{Fe} 4 \mathrm{~S}]^{2+}-\mathrm{Met}$ and the powerful oxidant $5^{\prime}-\mathrm{dA}^{\bullet}$. The latter can abstract a hydrogen atom (H.) from the $\mathrm{C} 6$ atom of the octanoyl substrate. Then, the C6 radical will be attacked by a nearby $\mathrm{S}^{2-}$ ion of auxiliary FeS cluster in the first $\mathrm{S}$-insertion reaction. This will reduce the auxiliary $\mathrm{FeS}$ cluster to the $[4 \mathrm{Fe} 4 \mathrm{~S}]^{+}$state. The first half-reaction is completed by the dissociation of one $\mathrm{Fe}^{2+}$ ion from the auxiliary cluster and a one-electron oxidation, giving the $[3 \mathrm{Fe} 3 \mathrm{~S}]^{0}$ state with one $\mathrm{Fe}^{3+}$ and two $\mathrm{Fe}^{2+}$ ions.

The second half-reaction starts with the dissociation of the Met and 5'-dA products and the binding of a new AdoMet molecule. Again, the reaction is started by the

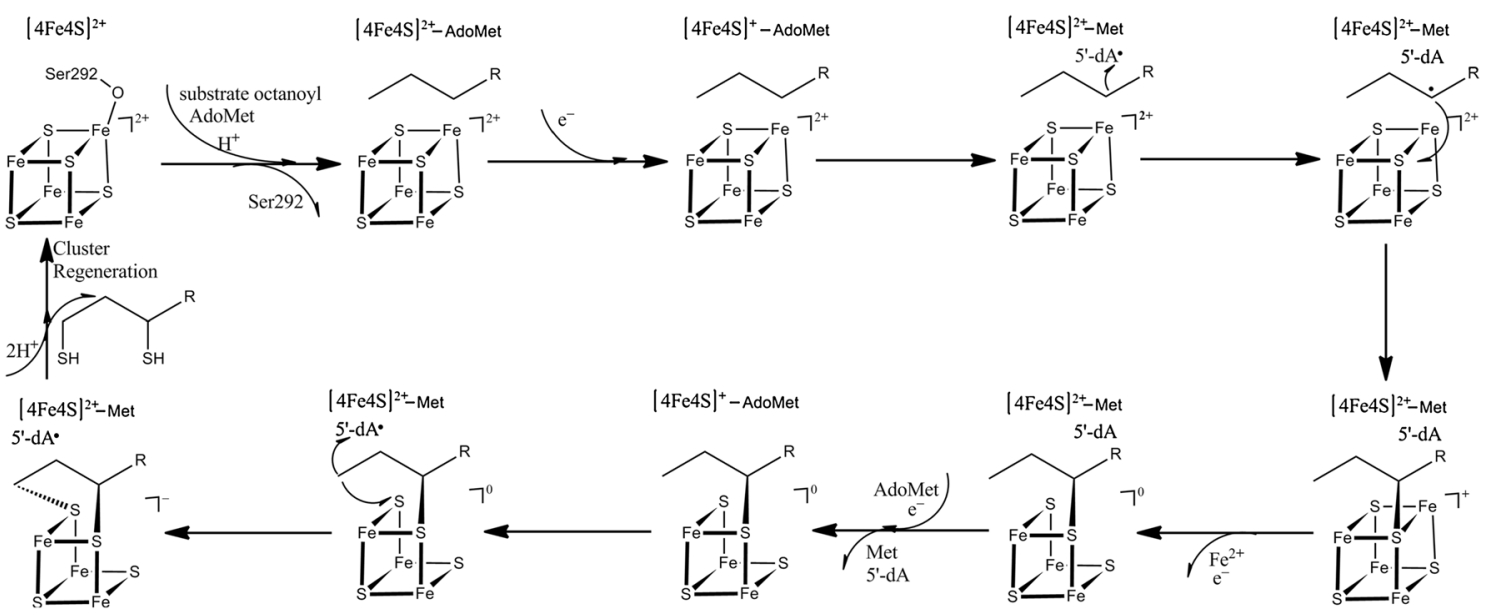

Scheme 2 The proposed reaction mechanism for LipA, showing the main FeS cluster on the top and the auxiliary FeS cluster in full detail at the bottom 
reduction of the main $\mathrm{FeS}$ cluster to the $[4 \mathrm{Fe} 4 \mathrm{~S}]^{+}$state, which triggers the cleavage of the $\mathrm{C} 5^{\prime}-\mathrm{S}$ bond in AdoMet, leading to the formation of $5^{\prime}-\mathrm{dA}^{\bullet}$. Next, $5^{\prime}$-dA ${ }^{\bullet}$ abstracts one hydrogen atom from $\mathrm{C} 8$ of the octanoyl substrate, generating a $\mathrm{C} 8$ radical, which will be attacked by another $\mathrm{S}^{2-}$ ion of the auxiliary FeS cluster. This produces the final product lipoyl and the auxiliary FeS cluster in the fully reduced $[3 \mathrm{Fe} 3 \mathrm{~S}]^{-}$state. Finally, the product can be released by binding two protons and a new auxiliary [4Fe $4 \mathrm{~S}]$ cluster needs to be regenerated before the enzyme is functional again.

In this paper, we have investigated this reaction mechanism of LipA with combined quantum mechanical and molecular mechanics (QM/MM) calculations. This allows us to understand how the redox and spin states of the FeS clusters change during the reaction mechanism, as well as how the sulfur ions of the auxiliary FeS cluster attack the octanoyl substrate.

\section{Methods}

\section{The protein}

All calculations were based on the 1.64 and $1.86-\AA$ crystal structures of lipoyl synthase from Mycobacterium tuberculosis (PDB codes 5EXJ and 5EXK); the former is in the resting state and the latter is in an intermediate state, after the formation of the first C-S bond [11]. The crystal structure of resting state is a monomer, in which one molecule of dithiothreitol (DTT) binds to the main [4Fe4S] cluster. It was replaced by a water molecule in our calculations. In the crystal of the intermediate state, there are six independent proteins in the asymmetric unit, and we used chains A and B in our calculations. Chain B is a short octapeptide containing the octanoyl substrate, modelling the lipoyl carrier protein.

The setup of the enzyme was the same as in our previous calculations [34, 35]. The protonation states of all the residues were determined using PROPKA [36] and by a detailed study of the solvent accessibility, the hydrogen-bond pattern, and the possible formation of ionic pairs. They were the same in both the resting and the intermediate states. All Arg, Lys, Asp, and Glu residues were assumed to be charged. Cysteine ligands coordinating to metals were deprotonated. Among the His residues, His52 and 256 were assumed to be protonated on the NE2 atom, His179 was assumed be protonated on ND1, whereas His257 was modelled as doubly protonated. In addition, Ser292 in the resting state was deprotonated, because it binds to an Fe ion of auxiliary FeS cluster.

The protein was protonated and solvated with water molecules forming a sphere with a radius of $35 \AA$ around the geometric centre using the leap module of the Amber software package ( 15000 atoms in total) [37]. The added protons and water molecules were optimised by a 120 -ps simulated annealing calculation, followed by a minimisation, keeping the other atoms fixed at their crystal-structure positions. The protein was described by the Amber ff14SB force field [38] and water molecules with the TIP3P model [39]. No bonds were defined between the metal ions and their ligands (because they were kept fixed in the simulations).

\section{QM calculations}

All QM calculations were performed with the Turbomole 7.1 software [40]. Two DFT methods, TPSS [41] and B3LYP [42-44], and two different basis sets were used, def2-SV(P) [45] and def2-TZVP [46]. The calculations were sped up by expanding the Coulomb interactions in an auxiliary basis set, the resolution-of-identity (RI) approximation [47, 48]. All the calculations used a QM system consisting of the two [4Fe4S] clusters with all the first-sphere ligands (shown in Fig. 1). The Cys and Ser residues in the QM region were truncated by converting the $\mathrm{CA}$ atom to a hydrogen atom. In the intermediate state, the QM system was extended by the full AdoMet molecule, as well as the octanoyl substrate, which were modelled as shown in Fig. 1. To find all the possible BS states, two approaches were employed, viz. the fragment method developed by Szilagyi and Winslow, as implemented in the local program makebs [49], and a rapid

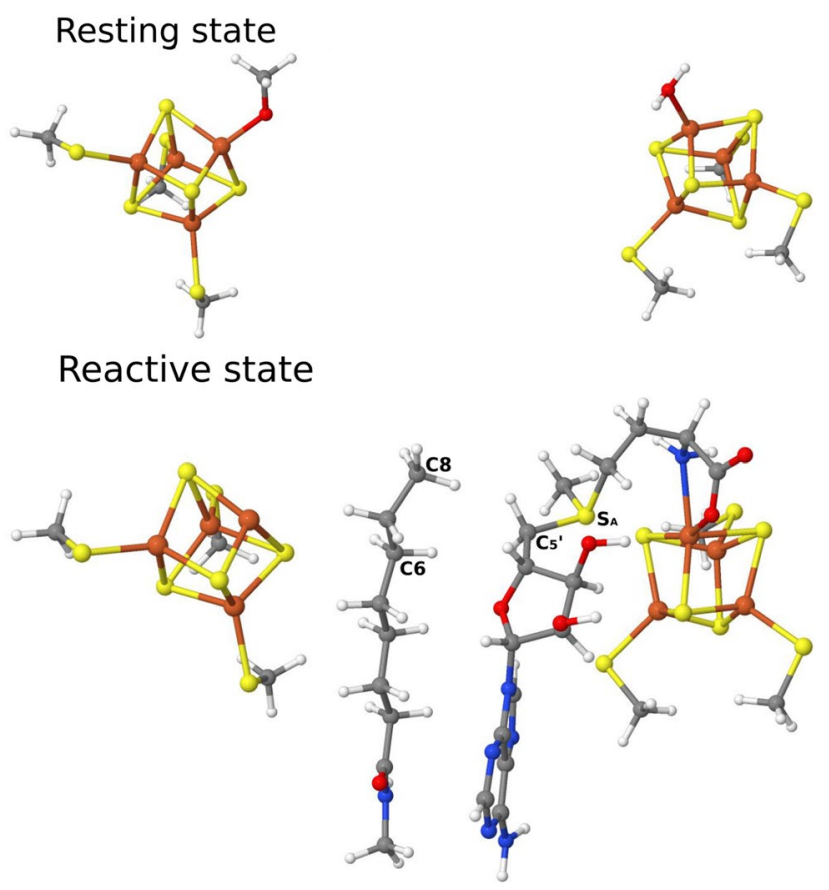

Fig. 1 QM regions employed in the QM/MM calculations of the resting and reactive states, respectively. The auxiliary FeS cluster is shown to the left 
generation of various BS states based on swapping the Fe ion coordinates [50].

\section{QM/MM calculations}

The QM/MM calculations were performed with the ComQum software [51, 52]. In this approach, the protein and solvent are split into two subsystems: System 1 (the QM region) was relaxed by QM methods. It contained the same atoms as the vacuum QM calculations (shown in Fig. 1). System 2 contained the remaining part of the protein and the solvent. It was kept fixed at the original (crystallographic) positions.

In the QM calculations, system 1 was represented by a wavefunction, whereas all the other atoms were represented by an array of partial point charges, one for each atom, taken from MM libraries. Thereby, the polarisation of QM region by the surroundings is included in a selfconsistent manner (electrostatic embedding). When there is a bond between systems 1 and 2 (a junction), the hydrogen link-atom approach was employed: The QM region was capped with hydrogen atoms (hydrogen link atoms, $\mathrm{HL}$ ), the position of which are linearly related to the corresponding atom (carbon link atoms, CL) in the full system $[52,53]$. All atoms were included in the point-charge model, except the CL atoms [54].

The total QM/MM energy in ComQum was calculated as $[51,52]$

$E_{\mathrm{QM} / \mathrm{MM}}=E_{\mathrm{QM} 1+\mathrm{ptch} 2}^{\mathrm{HL}}+E_{\mathrm{MM} 12, q_{1}=0}^{\mathrm{CL}}-E_{\mathrm{MM} 1, q_{1}=0}^{\mathrm{HL}}$,

where $E_{\mathrm{QM} 1+\text { ptch2 }}^{\mathrm{HL}}$ is the $\mathrm{QM}$ energy of the $\mathrm{QM}$ region truncated by HL atoms and embedded in the set of point charges modelling system 2 (but excluding the self-energy of the point charges). $E_{\mathrm{MM} 1, q_{1}=0}^{\mathrm{HL}}$ is the MM energy of the QM system, still truncated by HL atoms, but without any electrostatic interactions. Finally, $E_{\mathrm{MM} 12, q_{1}=0}^{\mathrm{CL}}$ is the classical energy of all atoms in the system with CL atoms and with the charges of the QM system set to zero (to avoid double counting of the electrostatic interactions). By this approach, which is similar to the one used in the ONIOM method [55], errors caused by the truncation of the QM system should cancel.

The geometry optimisations were continued until the energy change between two iterations was less than $2.6 \mathrm{~J} /$ mol $\left(10^{-6}\right.$ a.u. $)$ and the maximum norm of the Cartesian gradients was below $10^{-3}$ a.u. The QM calculations were carried out using the Turbomole 7.1 software [40]. Geometry optimisation was performed using the TPSS [41] functional in combination with def2-SV(P) [45] basis set, including the empirical DFT-D3 dispersion correction in Turbomole [56]. The MM calculations were performed with the Amber software, using the Amber ff14SB force field [38].
Reported energies are $\mathrm{QM} / \mathrm{MM}$ energies obtained at the TPSS/def2-SV(P) level, including dispersion and the MM correction $\left(E_{\mathrm{QM} / \mathrm{MM}}^{\mathrm{SV})}\right)$. This energy was then extrapolated to the B3LYP/def2-TZVP level using QM calculations with the same QM region and including the point-charge model:

$E_{\mathrm{tot}}=E_{\mathrm{QM} / \mathrm{MM}}^{\mathrm{SV}(\mathrm{P})}+E_{\mathrm{TPSS}}^{\mathrm{TZVP}}+E_{\mathrm{B} 3 \mathrm{LYP}}^{\mathrm{SV}(\mathrm{P})}-2 E_{\mathrm{TPSS}}^{\mathrm{SV}(\mathrm{P})}$

\section{Results and discussion}

In this paper, we have studied the reaction mechanism of LipA. We first discuss the spin state of the two $[4 \mathrm{Fe} 4 \mathrm{~S}]^{2+}$ cluster in the active site with and without the octanoyl substrate bound. Then, the determined ground state of FeS clusters will be used to investigate the mechanism of the two S-insertion reactions.

\section{The spin state of FeS cluster}

The properties of $[4 \mathrm{Fe} 4 \mathrm{~S}]^{2+}$ clusters have been studied extensively [17-33]. However, they can be affected by environment, e.g., different ligands binding to $\mathrm{Fe}$ ion or the protein surrounding. In this work, the QM/MM approach was employed, taking into account the surrounding protein and solvent. In the resting state, both clusters are in the $[4 \mathrm{Fe} 4 \mathrm{~S}]^{2+}$ oxidation state, i.e., each with two reduced $\mathrm{Fe}^{2+}$ and two oxidised $\mathrm{Fe}^{3+}$ ions. This gives a total of $4 \times(4+5)=36$ unpaired spins in the high-spin state, which can be combined in many different ways. We tried several spin states and in agreement with the previous studies, our results indicate that the lowest energy is obtained if both clusters are in the singlet state with antiferromagnetically coupled high-spin $\mathrm{Fe}$ ions (i.e., two ions with a surplus of spin up and two ions with a surplus of spin down). Mulliken spin analysis indicated that each $\mathrm{Fe}$ ion had approximately four unpaired spins each, either positive or negative.

In each cluster, two Fe ions with spin up (and two with spin down) can be selected in six different ways, as shown in Fig. 2. Since the two clusters are quite far away $(\sim 12 \AA)$, we first varied the spin state of the auxiliary cluster, keeping that of the main cluster constant. Then, we determined the most stable state for the main cluster. For each state, the geometries were optimised with QM(TPSS/def2-SV(P))/MM approach. The resulting energies are collected in Table 1. It can be seen that the spin state $[\downarrow \uparrow \uparrow \downarrow]$ is predicted to be most stable for the auxiliary cluster and that the energies vary by up to $9 \mathrm{~kJ} / \mathrm{mol}$ for the resting state when the spin of main FeS cluster is kept fixed. Then, we fixed the spin state of auxiliary cluster at the most stable state and varied the spin of the main cluster. As can be seen in Table 1, this gave a 
Fig. 2 Six possible spin states of each of the $[4 \mathrm{Fe} 4 \mathrm{~S}]^{2+}$ clusters in the resting state of LipA (main cluster to the left, auxiliary cluster to the right). The arrows indicate whether the Fe ions have a surplus of spin up or down
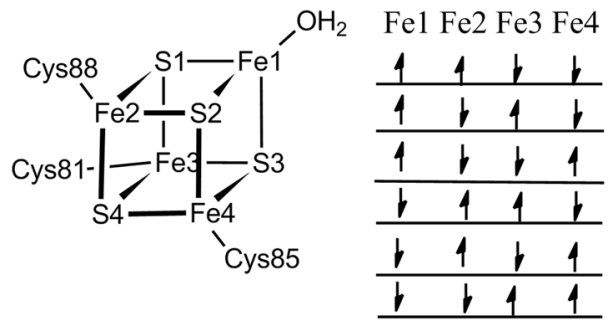

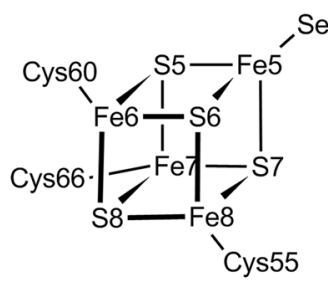

Ser292

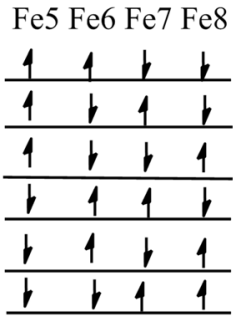

Table 1 Energies for various spin state of two FeS clusters in the resting and reactive states of LipA (in $\mathrm{kJ} / \mathrm{mol}$ ). The arrows show the spin states of $\mathrm{Fe}$ ions, in the order $\mathrm{Fe} 1-\mathrm{Fe} 8$, according to the numbering in Fig. 2

\begin{tabular}{lccc}
\hline Fixed spin & Spin state & \multicolumn{2}{l}{ Energy (kJ/mol) } \\
\cline { 2 - 4 } & & Resting state & Reactive state \\
\hline Main cluster & $\uparrow \downarrow \uparrow \downarrow \downarrow \uparrow \downarrow \uparrow$ & 0 & 0 \\
& $\uparrow \downarrow \uparrow \downarrow \uparrow \downarrow \downarrow \uparrow$ & -4.7 & 23.7 \\
& $\uparrow \downarrow \uparrow \downarrow \uparrow \uparrow \downarrow \downarrow$ & 2.7 & 37.4 \\
& $\uparrow \downarrow \uparrow \downarrow \downarrow \downarrow \uparrow \uparrow$ & 1.9 & 0.4 \\
& $\uparrow \downarrow \uparrow \downarrow \downarrow \uparrow \uparrow \downarrow$ & -5.9 & -2.1 \\
Auxiliary cluster & $\uparrow \downarrow \uparrow \downarrow \uparrow \downarrow \uparrow \downarrow$ & -0.9 & 21.2 \\
& $\downarrow \uparrow \uparrow \downarrow \downarrow \uparrow \uparrow \downarrow$ & -19.3 & 1.8 \\
& $\downarrow \downarrow \uparrow \uparrow \downarrow \uparrow \uparrow \downarrow$ & -18.9 & - \\
& $\uparrow \uparrow \downarrow \downarrow \downarrow \uparrow \uparrow \downarrow$ & -17.7 & -9.1 \\
& $\uparrow \downarrow \downarrow \uparrow \downarrow \uparrow \uparrow \downarrow$ & -14.4 & 0.7 \\
& $\downarrow \uparrow \downarrow \uparrow \downarrow \uparrow \uparrow \downarrow$ & -7.6 & 5.1 \\
\hline
\end{tabular}

slightly larger variation in the energies by up to $13 \mathrm{~kJ} / \mathrm{mol}$. Interestingly, three states had nearly the same energy (within $2 \mathrm{~kJ} / \mathrm{mol}$ ), so it is hard to pinpoint which of these three states is the ground state.

Next, we examined the spin states for the reactive state, in which AdoMet and the octanoyl substrate have bound to the active site of LipA, and Ser292 and the water ligand have dissociated from the FeS clusters. In addition, the main cluster was reduced by one electron to the $[4 \mathrm{Fe} 4 \mathrm{~S}]^{+}$ state. This species is ready for the cleavage of $\mathrm{C}_{5}{ }^{\prime}-\mathrm{S}_{\mathrm{A}}$ bond in AdoMet. As shown in Fig. 1, the AdoMet group binds to the Fe ion that was bound by a water molecule in resting state. To compare with the resting state, calculations with the same spins states as for the resting state were performed. The energies are also shown in Table 1. As for the resting state, the $[\downarrow \uparrow \uparrow \downarrow]$ state is predicted to be most stable for the auxiliary cluster. However, the energies vary much more than for the resting state, by up to $40 \mathrm{~kJ} / \mathrm{mol}$. In particular, it can be seen that all states with Fe 5 spin up are high in energy. In the reactive state, this ion is coordinated by only three $\mathrm{S}^{2-}$ ions, whereas the other $\mathrm{Fe}$ ions in this cluster also are bound to a Cys residue and it is also the ion that dissociates during the first $\mathrm{S}$-insertion reaction. When this ion has a negative spin, the spin density is also lower (in absolute terms, e.g., - 3.4 with B3LYP) than for all the other Fe ions (3.6-3.8). However, when it has positive spin, it does no longer have a lower spin than the other $\mathrm{Fe}$ ions. The effect is especially pronounced at the B3LYP level of theory and the energy difference between the states with positive or negative spin on $\mathrm{Fe} 5$ increases by $14-22 \mathrm{~kJ} / \mathrm{mol}$ with this functional.

The spin states of main cluster were also examined in the same way with the most stable spin state of auxiliary cluster. From Table 1, it can be seen that the variation in the energies is similar to that of the resting state, up to $14 \mathrm{~kJ} / \mathrm{mol}$. For the reactive state, the $[\uparrow \uparrow \downarrow \downarrow \downarrow \uparrow \uparrow \downarrow]$ spin state gives the lowest energy and it is $7 \mathrm{~kJ} / \mathrm{mol}$ lower than any other state. However, we could not locate the species with the $[\downarrow \downarrow \uparrow \uparrow \downarrow \uparrow \uparrow \downarrow]$ spin state, because the S-C bond of AdoMet was cleaved during geometry optimisation, even if we first fixed the distance. To estimate the energy of this state, we performed a calculation for $[\uparrow \downarrow \uparrow \downarrow \downarrow \uparrow \uparrow \downarrow]$ state, using the second lowest spin state of the auxiliary cluster. It was $11 \mathrm{~kJ} / \mathrm{mol}$ higher than the $[\uparrow \uparrow \downarrow \downarrow \downarrow \uparrow \uparrow \downarrow]$ state. Since the $[\downarrow \uparrow \downarrow \uparrow]$ state is $2 \mathrm{~kJ} / \mathrm{mol}$ higher than $[\downarrow \uparrow \uparrow \downarrow]$ state in auxiliary cluster, it can be estimated that $[\downarrow \downarrow \uparrow \uparrow \downarrow \uparrow \uparrow \downarrow]$ state is roughly $8 \mathrm{~kJ} / \mathrm{mol}$ less stable than $[\uparrow \uparrow \downarrow \downarrow \downarrow \uparrow \uparrow \downarrow]$ state. Therefore, we can conclude that the $[\uparrow \uparrow \downarrow \downarrow \downarrow \uparrow \uparrow \downarrow]$ state is the most stable state in the reactive state and among the three lowest states for the resting state. Therefore, we used this state for the study of the reaction mechanism and we will call it the reactive spin state (RSS) throughout this paper.

The Fe- $\mathrm{S}^{2-}$ bond lengths in the two FeS clusters with the RSS spin state in resting and reactive states are shown in Table 2. For the resting state, the three Fe1-S bond lengths in the main cluster are 2.27-2.35 $\AA$, which are slightly shorter than the corresponding bond lengths of Fe2-S (2.30-2.38 ̊), Fe3-S (2.28-2.37 $\AA$ ) and Fe4-S $(2.27-2.36 \AA)$. This is caused by the fact that Fe1 binds a water molecule, whereas the others are bound to Cys residues. On the other hand, the Fe1-S bonds (2.30-2.43 $\AA$ ) became longer when AdoMet binds to $\mathrm{Fe} 1$ in the reactive state with both the carboxylate $\mathrm{O}$ atom. For the auxiliary cluster in the resting state, $\mathrm{Fe} 5$ binds to a Ser residue and consequently, the Fe5-S bonds are slightly longer than the other $\mathrm{Fe}-\mathrm{S}$ bonds. On the other hand, for the reactive state, the Fe5-S bonds in the auxiliary cluster become shortest 
Table 2 Fe-ligand distances (in $\AA$ ) of FeS clusters in the resting and reactive states with the RSS spin state

\begin{tabular}{|c|c|c|c|c|c|}
\hline \multicolumn{3}{|c|}{ Main FeS cluster } & \multicolumn{3}{|c|}{ Auxiliary FeS cluster } \\
\hline Bond & Resting state & Reactive state & Bond & Resting state & Reactive state \\
\hline $\mathrm{Fe} 1-\mathrm{S} 1$ & 2.32 & 2.43 & Fe5-S5 & 2.31 & 2.28 \\
\hline $\mathrm{Fe} 1-\mathrm{S} 2$ & 2.35 & 2.37 & Fe5-S6 & 2.37 & 2.27 \\
\hline $\mathrm{Fe} 1-\mathrm{S} 3$ & 2.27 & 2.30 & Fe5-S7 & 2.35 & 2.27 \\
\hline $\mathrm{Fe} 1-\mathrm{O}_{\mathrm{W}}^{\mathrm{a}}$ & 2.12 & - & $\mathrm{Fe} 5-\mathrm{O}_{\mathrm{Ser}}$ & 1.86 & - \\
\hline $\mathrm{Fe} 1-\mathrm{O}_{\mathrm{A}}^{\mathrm{b}}$ & - & 2.18 & & & \\
\hline $\mathrm{Fe} 1-\mathrm{N}_{\mathrm{A}}^{\mathrm{c}}$ & - & 2.28 & & & \\
\hline $\mathrm{Fe} 2-\mathrm{S} 1$ & 2.35 & 2.33 & Fe6-S5 & 2.35 & 2.36 \\
\hline $\mathrm{Fe} 2-\mathrm{S} 2$ & 2.38 & 2.34 & Fe6-S6 & 2.27 & 2.31 \\
\hline $\mathrm{Fe} 2-\mathrm{S} 4$ & 2.30 & 2.27 & Fe6-S8 & 2.34 & 2.34 \\
\hline $\mathrm{Fe} 2-\mathrm{S}_{\mathrm{Cys}}$ & 2.28 & 2.32 & $\mathrm{Fe} 6-\mathrm{S}_{\mathrm{Cys}}$ & 2.28 & 2.29 \\
\hline Fe3-S1 & 2.28 & 2.30 & Fe7-S5 & 2.36 & 2.37 \\
\hline Fe3-S3 & 2.34 & 2.35 & Fe7-S7 & 2.25 & 2.32 \\
\hline $\mathrm{Fe} 3-\mathrm{S} 4$ & 2.37 & 2.34 & Fe7-S8 & 2.37 & 2.37 \\
\hline $\mathrm{Fe} 3-\mathrm{S}_{\mathrm{Cys}}$ & 2.28 & 2.29 & $\mathrm{Fe} 7-\mathrm{S}_{\mathrm{Cys}}$ & 2.27 & 2.26 \\
\hline $\mathrm{Fe} 4-\mathrm{S} 2$ & 2.27 & 2.30 & Fe8-S6 & 2.36 & 2.35 \\
\hline $\mathrm{Fe} 4-\mathrm{S} 3$ & 2.34 & 2.36 & Fe8-S7 & 2.34 & 2.36 \\
\hline $\mathrm{Fe} 4-\mathrm{S} 4$ & 2.36 & 2.33 & Fe8-S8 & 2.25 & 2.24 \\
\hline $\mathrm{Fe} 4-\mathrm{S}_{\mathrm{Cys}}$ & 2.33 & 2.29 & $\mathrm{Fe} 8-\mathrm{S}_{\mathrm{Cys}}$ & 2.29 & 2.28 \\
\hline
\end{tabular}

${ }^{a} \mathrm{O}_{\mathrm{w}}$ is the oxygen atom in water

${ }^{\mathrm{b}} \mathrm{O}_{\mathrm{A}}$ is one of the carboxylate oxygen atoms in AdoMet

${ }^{\mathrm{c}} \mathrm{N}_{\mathrm{A}}$ is the amine nitrogen atom in AdoMet
(2.27-2.28 $\AA$ ), because no other groups bind to Fe5 except the three $\mathrm{S}^{2-}$ ions.

\section{The mechanism of LipA}

In the reactive state $\left(\mathrm{RS}_{1}\right)$, AdoMet and the octanoyl substrate are bound to the active site of LipA and the auxiliary FeS cluster has been reduced. For convenience, we describe the states of the $\mathrm{FeS}$ clusters as $\left[2 \mathrm{Fe}^{2+} 2 \mathrm{Fe}^{3+} 4 \mathrm{~S}^{2-}\right]$ and $\left[3 \mathrm{Fe}^{2+} \mathrm{Fe}^{3+} 4 \mathrm{~S}^{2-}\right]$, even if the redox states of individual $\mathrm{Fe}$ ions cannot be discerned.

\section{The first S-insertion reaction}

The reduction of the main FeS cluster is beneficial for the transfer of one electron to AdoMet and cleavage of the $\mathrm{C}_{5}{ }^{\prime}-\mathrm{S}_{\mathrm{A}}$ bond of AdoMet. Our calculations indicate that cleavage of the $\mathrm{C}_{5}{ }^{\prime}-\mathrm{S}_{\mathrm{A}}$ bond is heterolytic and very facile, with an energy barrier of only $6 \mathrm{~kJ} / \mathrm{mol}$ and an exothermicity of $42 \mathrm{~kJ} / \mathrm{mol}$. During the reaction, one electron transferred from the main FeS cluster to AdoMet, producing $5^{\prime}-\mathrm{dA}^{\bullet}$ and both $\mathrm{FeS}$ clusters in the $\left[2 \mathrm{Fe}^{2+} 2 \mathrm{Fe}^{3+} 4 \mathrm{~S}^{2-}\right]$ oxidation state (i.e., the same as the resting state). The resulting $\mathrm{IM}_{1}$ state (the subscript 1 indicates that it belongs to the first S-insertion reaction) is shown in Fig. 3. It has a $\mathrm{C}_{5}{ }^{\prime}-\mathrm{S}_{\mathrm{A}}$ distance of $3.5 \AA$, whereas the $\mathrm{C}_{5}{ }^{\prime}-\mathrm{H} 6$ distance is $2.2 \AA$. The $S_{\mathrm{A}}$ atom coordinates weakly to $\mathrm{Fe} 1$ with a distance of $2.8 \AA$.

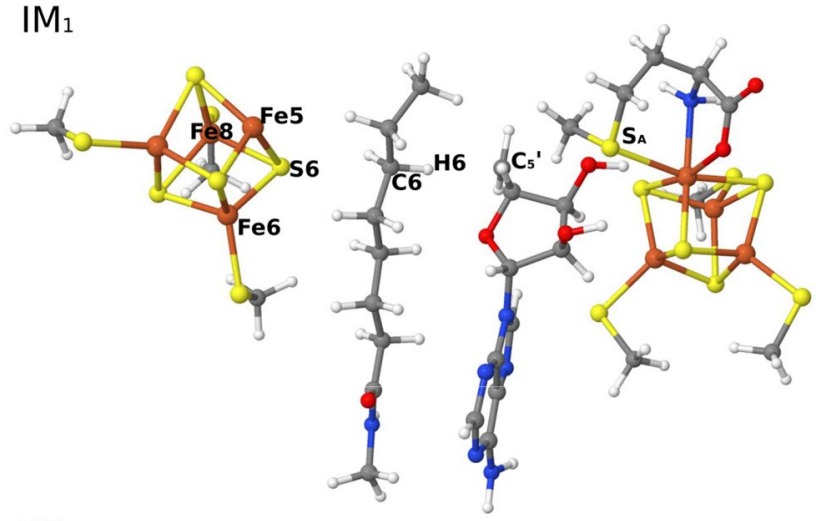

$\mathrm{PS}_{1}$

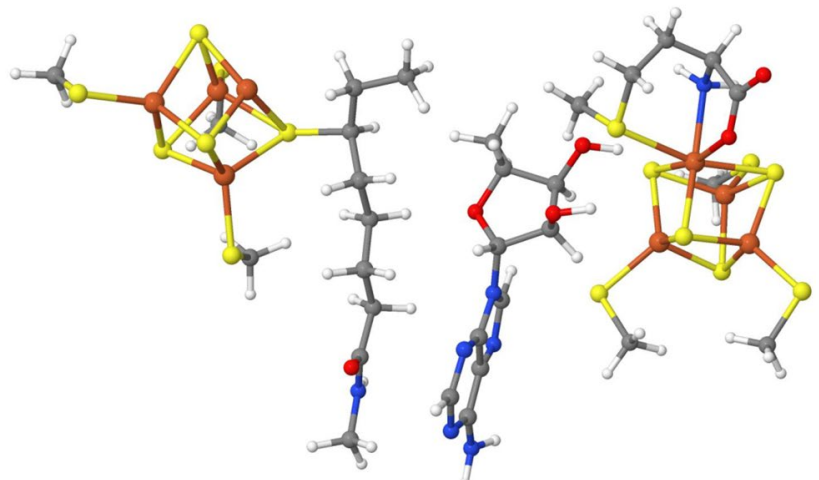

Fig. 3 Structures of the $\mathrm{IM}_{1}$ intermediate and the $\mathrm{PS}_{1}$ product of the first $\mathrm{S}$-insertion reaction 
Next, the powerful oxidant $5^{\prime}$-dA ${ }^{\bullet}$ abstracts $\mathrm{H} 6$ from the $\mathrm{C} 6$ atom of the octanoyl substrate. The product of this reaction $\left(\mathrm{PS}_{1}\right)$ is also shown in Fig. 3. The energy barrier was $37 \mathrm{~kJ} / \mathrm{mol}$. Interestingly, the substrate radical (C6 radical, Scheme 2) was not an intermediate state. Instead, C6 binds directly to $\mathrm{S} 6$ of the auxiliary FeS cluster, so that the first $\mathrm{S}$-insertion product is directly generated. This $\mathrm{PS}_{1}$ state was $184 \mathrm{~kJ} / \mathrm{mol}$ lower in energy than the reactive state. The S6-Fe5, S6-Fe6, and S6-Fe8 bond distances are 2.41, 2.40, and $2.56 \AA$ in $\mathrm{PS}_{1}$ state, which are longer than in $\mathrm{IM}_{1}$ state (2.27, 2.28, and $2.34 \AA$, respectively), indicating that the formation of the S6-C6 bond weakens the S6-Fe bonds. In addition, during the $\mathrm{S}$-insertion reaction, one electron is transferred from substrate to the main $\mathrm{FeS}$ cluster, leaving it in the reduced $\left[3 \mathrm{Fe}^{2+} \mathrm{Fe}^{3+} 4 \mathrm{~S}^{2-}\right]$ state.

\section{The second S-insertion reaction}

Before the insertion of the second sulfur atom to the $\mathrm{C} 8$ atom of the octanoyl substrate, one of the $\mathrm{Fe}^{2+}$ ions should dissociate. In addition, 5'-dA and Met need to be replaced by a new molecule of AdoMet and the active site should be oxidised, generating a $\left[\mathrm{Fe}^{2+} 2 \mathrm{Fe}^{3+} 4 \mathrm{~S}^{2-}\right]$-substrate complex, which has been characterised by EPR spectroscopy $[11,12,57]$. The optimised $\mathrm{RS}_{2}$ species is shown in Fig. 4. The two FeS clusters are in the $\left[2 \mathrm{Fe}^{2+} 2 \mathrm{Fe}^{3+} 4 \mathrm{~S}^{2-}\right]$ and $\left[\mathrm{Fe}^{2+} 2 \mathrm{Fe}^{3+} 4 \mathrm{~S}^{2-}\right]$ states. Again, the cleavage of the $\mathrm{C}_{5}{ }^{\prime}-\mathrm{S}_{\mathrm{A}}$ bond of AdoMet was triggered by reducing the main $\mathrm{FeS}$ cluster by one electron. Interestingly, the reduction led directly to cleavage of the $\mathrm{C}_{5}{ }^{\prime}-\mathrm{S}_{\mathrm{A}}$ bond without any barrier, giving rise to $\mathrm{IM} 1_{2}$ (even if we first fixed the $\mathrm{C}_{5}{ }^{\prime}-\mathrm{S}_{\mathrm{A}}$ bond length). The IM1 $1_{2}$ species is also shown in Fig. 4 and has a $\mathrm{C}_{5}{ }^{\prime}-\mathrm{H} 8$ distance of $2.6 \AA$. It is $101 \mathrm{~kJ} / \mathrm{mol}$ more stable than the reduced $\mathrm{RS}_{2}$ state (obtained by fixing the $\mathrm{C}_{5}{ }^{\prime}-\mathrm{S}_{\mathrm{A}}$ bond length to $1.9 \AA$ ). We also studied the cleavage of the $\mathrm{C}_{5}{ }^{\prime}-\mathrm{S}_{\mathrm{A}}$ bond of AdoMet in $\mathrm{RS}_{2}$ state (before the one-electron reduction): It had an energy barrier of $18 \mathrm{~kJ} / \mathrm{mol}$ and the reaction was exothermic by $62 \mathrm{~kJ} / \mathrm{mol}$. Thus, one-electron reduction of $\mathrm{RS}_{2}$ leads to a more facile reaction mechanism, but it is not necessary from an energetic point of view.

In the next step, the $\mathrm{C}_{5}{ }^{\prime}$ radical abstracted the $\mathrm{H} 8$ atom from the octanoyl substrate. In variance to the first S-insertion reaction, we found an intermediate $\mathrm{IM} 2_{2}$ with a radical on the $\mathrm{C} 8$ atom. It was $24 \mathrm{~kJ} / \mathrm{mol}$ more stable than $\mathrm{IM}_{2}$ and the barrier was $71 \mathrm{~kJ} / \mathrm{mol}$.

In the $\mathrm{IM} 22_{2}$ state, the $\mathrm{C} 8$ radical can be attacked by either the S1 or S3 atom from the auxiliary FeS cluster. However, the $\mathrm{C} 8$ atom is quite far from both ions, 5.1 and $5.4 \AA$. Therefore, the substrate has to rotate around the $\mathrm{C} 6-\mathrm{C} 7$ bond before the reaction is possible, giving rise to a third intermediate (IM2 ${ }_{2}^{\prime}$ in Fig. 6). Since the Ser291,
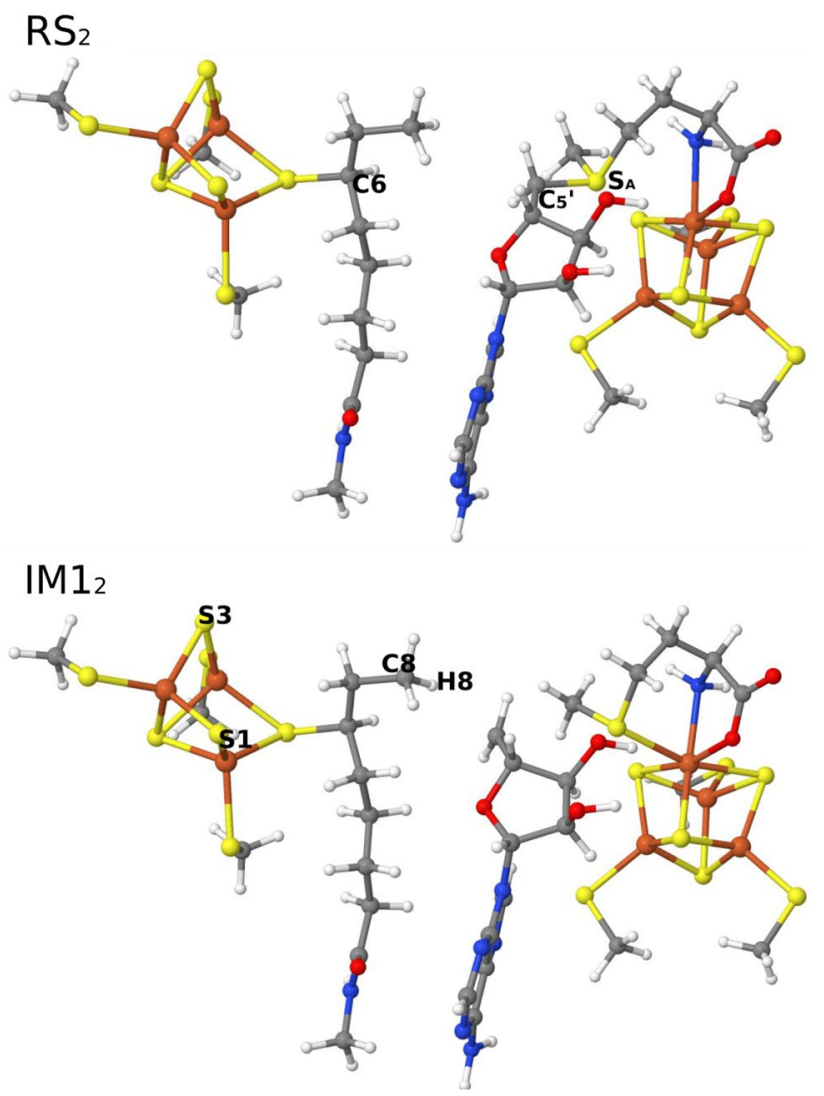

Fig. $4 \mathrm{RS}_{2}$ and $\mathrm{IM} 1_{2}$ structures in the second S-insertion reaction

Ser 292, and Tyr293 residues (in the MM system) are close to the substrate, they were allowed to relax in the QM/MM calculation. The resulting IM2 ${ }_{2}{ }^{\prime}$ state was $20 \mathrm{~kJ} / \mathrm{mol}$ less stable than $\mathrm{IM} 22_{2}$. This leads to distances of $\mathrm{S} 1-\mathrm{C} 8=3.3$ $\AA$ and $\mathrm{S} 3-\mathrm{C} 8=3.7 \AA$, respectively. For the next step, two mechanisms were examined, viz. attack by S1 (mechanism 1) or $S 3$ (mechanism 2). Our results indicate that mechanism 2 (Fig. 5) gave an $8 \mathrm{~kJ} / \mathrm{mol}$ lower energy barrier (34 vs. $42 \mathrm{~kJ} / \mathrm{mol}$ ) and a $26 \mathrm{~kJ} / \mathrm{mol}$ more stable product ( -95 vs. $-69 \mathrm{~kJ} / \mathrm{mol}$ ) than mechanism 1 . For the two transition states ( $\mathrm{TS} 3_{2}$ and $\left.\mathrm{TS} 3_{2}{ }^{\prime}\right)$, the $\mathrm{S} 1-\mathrm{C} 8$ distance was $2.5 \AA$ in mechanism 1 and the S3-C8 distance of $2.8 \AA$ in mechanism 2. In addition, the conformation of the substrate in $\mathrm{TS}_{3}{ }_{2}$ and $\mathrm{TS} 3_{2}{ }^{\prime}$ was different: the $\mathrm{H} 8_{1}-\mathrm{C} 8-\mathrm{C} 7-\mathrm{H} 7_{1}$ and $\mathrm{H} 8_{2}-\mathrm{C} 8-\mathrm{C} 7-\mathrm{H} 7_{2}$ dihedral angles were $2^{\circ}$ and $27^{\circ}$ in $\mathrm{TS} 3_{2}$, whereas they were $83^{\circ}$ and $70^{\circ}$ in $\mathrm{TS}_{2}{ }_{2}^{\prime}$. Similar differences were also found for the two products. These structural differences probably cause the lower barrier and more stable $\mathrm{PS} 2_{2}$ for mechanism 2.

The relative energies of all states in the reaction mechanism are collected in Fig. 6. It can be seen that the hydrogen abstraction by $5^{\prime}-\mathrm{dA}^{\bullet}$ had the highest energy barrier for both reactions, 37 and $71 \mathrm{~kJ} / \mathrm{mol}$ for the first and 
Fig. 5 Structures of $\mathrm{IM} 2_{2}$, $\mathrm{IM} 2{ }_{2}^{\prime}, \mathrm{PS} 1_{2}$, and $\mathrm{PS} 2_{2}$ in the second $\mathrm{S}$-insertion reaction

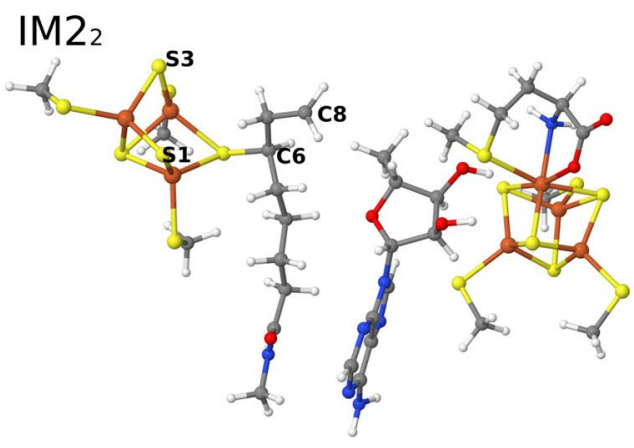

IM22'
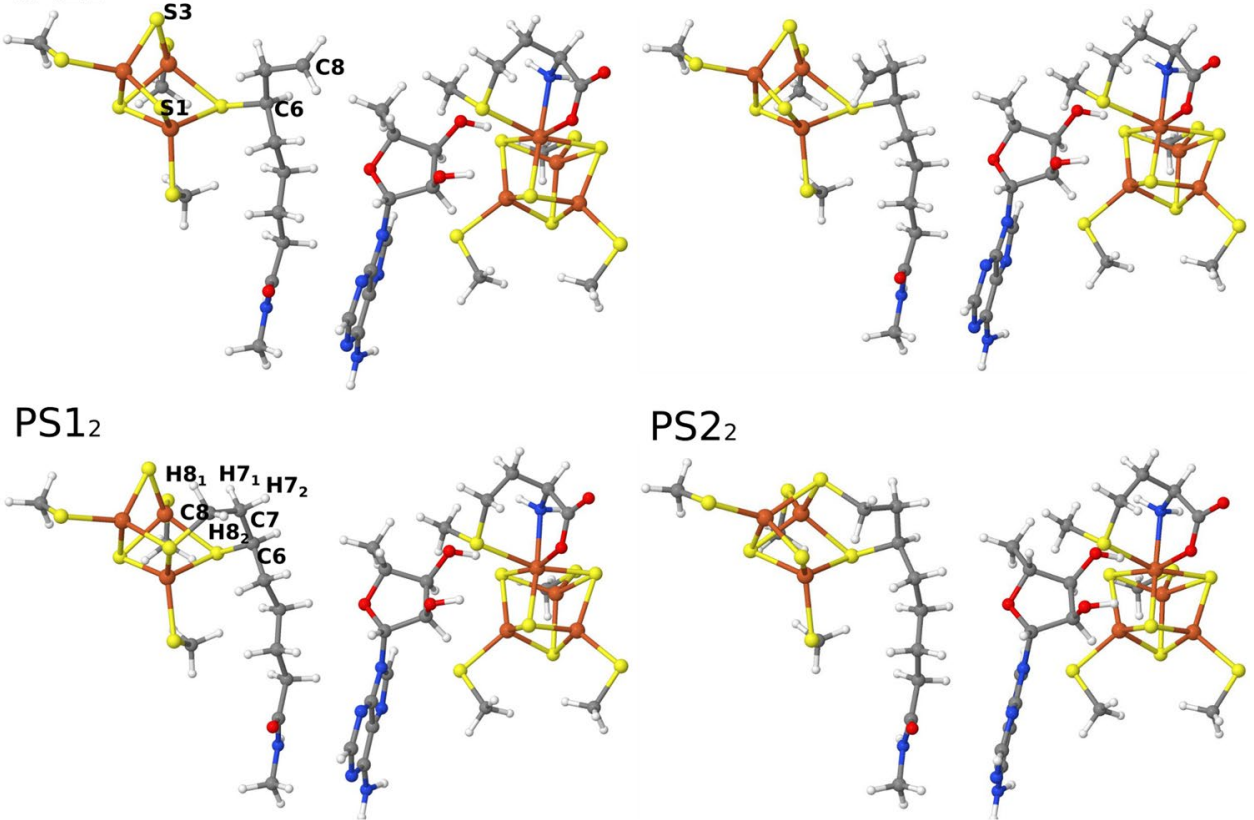

PS2 2
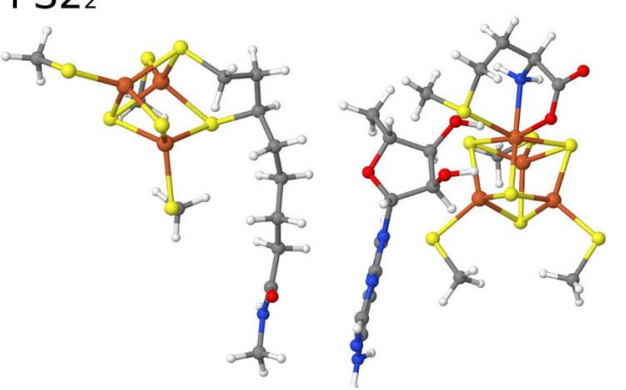

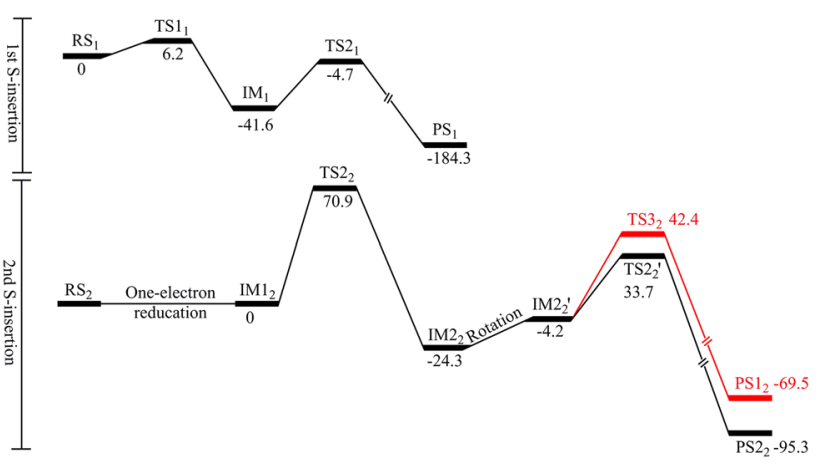

Fig. 6 Energy profile for the two S-insertion reaction mechanisms catalysed by LipA. Energies are $E_{\text {tot }}$ (Eq. 2) in $\mathrm{kJ} / \mathrm{mol}$

second S-insertion reactions, respectively. In addition, the two mechanisms are exothermic by 184 and $95 \mathrm{~kJ} / \mathrm{mol}$, respectively.

\section{Conclusion}

In this paper, we have studied the reaction mechanism of lipoyl synthase with the QM/MM approach. Geometry optimisations were performed with the QM(TPSS/def2$\mathrm{SV}(\mathrm{P})) / \mathrm{MM}$ approach. To obtain more accurate energies, single-point calculations were carried out at the B3LYP/ def2-SV(P) and TPSS/def2-TZVP levels of theory.

First, we have examined the spin states of the two FeS clusters in the active site of LipA, both in the resting state and in the reactive state. The singlet $[\uparrow \uparrow \downarrow \downarrow \downarrow \uparrow \uparrow \downarrow]$ spin state turned out to be the ground state. Our results indicate that the energies of the various BS states vary quite extensively. For example, if $\mathrm{Fe} 5$ in the auxiliary cluster of the reactive state is spin up, it will destabilise the system by 21-37 kJ/mol. In addition, the $\mathrm{Fe}-\mathrm{S}$ bond distances were somewhat shorter if water was the fourth ligand or if there was no fourth ligand. On the other hand, the $\mathrm{Fe}-\mathrm{S}$ bonds were slightly elongated when AdoMet bound to the Fe ion.

Second, we have investigated the mechanism for the formation of the $5^{\prime}-\mathrm{dA}^{\bullet}$ radical, which is a powerful oxidant. The activation energy was $6 \mathrm{~kJ} / \mathrm{mol}$ in first S-insert reaction, whereas $5^{\prime}-\mathrm{dA}^{\bullet}$ was generated without any barrier when the main cluster is reduced in the second S-insertion reaction. The difference between the first and second S-insertion reactions is that one $\mathrm{Fe}$ ion has dissociated from the auxiliary FeS cluster in latter reaction, which changes the redox state of FeS cluster and affects the reactivity of enzyme. The substrate is also bound to one of the sulfide ions of the auxiliary cluster.

Third, our results indicated that the attack of the $\mathrm{S}^{2-}$ ion on the $\mathrm{C} 6$ radical of the octanoyl substrate takes place in the same step as the transfer of $\mathrm{H} 6$ from substrate to $5^{\prime}-\mathrm{dA}{ }^{\bullet}$. In the second $\mathrm{S}$-insertion reaction, a $\mathrm{C} 8$ radical intermediate is formed and it has to change its conformation before it can react with one of the $\mathrm{S}^{2-}$ ions of the auxiliary cluster. Our calculations indicate that the reaction is more facile with the S3 ion than with the S1 ion and the energy barrier of the $\mathrm{S} 3$ ion attacking the $\mathrm{C} 8$ substrate radical is $30 \mathrm{~kJ} / \mathrm{mol}$. For both half-reactions, the abstraction of an $\mathrm{H}$ atom from the octanoyl substrate by the $5^{\prime}$-dA ${ }^{\bullet}$ radical is rate limiting, with barriers of 37 and $71 \mathrm{~kJ} / \mathrm{mol}$, respectively. 
Acknowledgements This investigation has been supported by grants from the Swedish research council (project 2014-5540), the China Scholarship Council, and COST through Action CM1305 (ECOSTBio). The computations were performed on computer resources provided by the Swedish National Infrastructure for Computing (SNIC) at Lunarc at Lund University.

Open Access This article is distributed under the terms of the Creative Commons Attribution 4.0 International License (http://creativecommons.org/licenses/by/4.0/), which permits unrestricted use, distribution, and reproduction in any medium, provided you give appropriate credit to the original author(s) and the source, provide a link to the Creative Commons license, and indicate if changes were made.

\section{References}

1. Reed LJ, Hackert ML (1990) J Biol Chem 265:8971-8974

2. White RH (1980) Biochemistry 19:15-19

3. Miller JR, Busby RW, Jordan SW, Cheek J, Henshaw TF, Ashley GW, Broderick JB, Cronan JE, Marletta MA (2000) Biochemistry 39:15166-15178

4. Cicchillo RM, Iwig DF, Jones AD, Nesbitt NM, BaleanuGogonea C, Souder MG, Tu L, Booker SJ (2004) Biochemistry 43:6378-6386

5. Douglas P, Kriek M, Bryant P, Roach PL (2006) Angew Chem Int Edit 45:5197-5199

6. Roach PL (2011) Curr Opin Chem Biol 15:267-275

7. Frey PA, Hegeman AD, Ruzicka FJ (2008) Crit Rev Biochem Mol Biol 43:63-88

8. Booker SJ, Cicchillo RM, Grove TL (2007) Curr Opin Chem Biol 11:543-552

9. Frey PA, Booker SJ (2001) Adv Protein Chem 58:1-45

10. Cicchillo RM, Lee KH, Baleanu-Gogonea C, Nesbitt NM, Krebs C, Booker SJ (2004) Biochemistry 43:11770-11781

11. McLaughlin MI, Lanz ND, Goldman PJ, Lee KH, Booker SJ, Drennan CL (2016) PNAS 113:9446-9450

12. Harmer JE, Hiscox MJ, Dinis PC, Fox SJ, Iliopoulos A, Hussey JE, Sandy J, Van Beek FT, Essex JW, Roach PL (2014) Biochem J 464:123-133

13. Lanz ND, Pandelia ME, Kakar ES, Lee KH, Krebs C, Booker SJ (2014) Biochemistry 53:4557-4572

14. Beinert H (2000) J Biol Inorg Chem 5:2-15

15. Beinert H, Holm RH, Munck E (1997) Science 277:653-659

16. Johnson DC, Dean DR, Smith AD, Johnson MK (2005) Annu Rev Biochem 74:247-281

17. Wang XB, Niu SQ, Yang X, Ibrahim SK, Pickett CJ, Ichiye T, Wang LS (2003) J Am Chem Soc 125:14072-14081

18. Solomon EI, Hedman B, Hodgson KO, Dey A, Szilagyi RK (2005) Coord Chem Rev 249:97-129

19. Dey A, Francis EJ, Adams MWW, Babini E, Takahashi Y, Fukuyama K, Hodgson KO, Hedman B, Solomon EI (2007) Science 318:1464-1468

20. Dey A, Glaser T, Moura JJG, Holm RH, Hedman B, Hodgson KO, Solomon EI (2004) J Am Chem Soc 126:16868-16878

21. Dey A, Glaser T, Couture MMJ, Eltis LD, Holm RH, Hedman B, Hodgson KO, Solomon EI (2004) J Am Chem Soc 126:8320-8328

22. Dey A, Peng Y, Broderick WE, Hedman B, Hodgson KO, Broderick JB, Solomon EI (2011) J Am Chem Soc 133:18656-18662

23. Calzolai L, Gorst CM, Bren KL, Zhou ZH, Adams MWW, LaMar GN (1997) J Am Chem Soc 119:9341-9350

24. Noodleman L, Case DA (1992) Adv Inorg Chem 38:423-470
25. Babini E, Bertini I, Borsari M, Capozzi F, Dikiy A, Eltis LD, Luchinat C (1996) J Am Chem Soc 118:75-80

26. Bergeler M, Stiebritz MT, Reiher M (2013) ChemPlusChem 78:1082-1098

27. Turker L, Erkoc S (2003) J Mol Struc-Theochem 623:17-21

28. Niu SQ, Ichiye T (2009) J Am Chem Soc 131:5724-5725

29. Niu SQ, Ichiye T (2009) J Phys Chem A 113:5671-5676

30. Noodleman L, Peng CY, Case DA, Mouesca JM (1995) Coord Chem Rev 144:199-244

31. Mouesca JM, Noodleman L, Case DA (1995) Int J Quantum Chem 56:95-102

32. Torres RA, Lovell T, Noodleman L, Case DA (2003) J Am Chem Soc 125:1923-1936

33. Chakrabarti M, Munck E, Bominaar EL (2011) Inorg Chem 50:4322-4326

34. Dong G, Ryde U (2016) J Biol Inorg Chem 21:383-394

35. Hu L, Söderhjelm P, Ryde U (2013) J Chem Theory Comput 9:640-649

36. Olsson MHM, Søndergaard CR, Rostkowski M, Jensen JH (2011) J Chem Theory Comput 7:525-537

37. Case DA, Berryman JT, Betz RM, Cerutti DS, Cheatham TE III, Darden TA, Duke RE, Giese TJ, Gohlke H, Goetz AW, Homeyer N, Izadi S, Janowski P, Kaus J, Kovalenko A, Lee TS, LeGrand S, Li P, Luchko T, Luo R, Madej B, Merz KM, Monard G, Needham P, Nguyen H, Nguyen HT, Omelyan I, Onufriev A, Roe DR, Roitberg A, Salomon-Ferrer R, Simmerling CL, Smith W, Swails J, Walker RC, Wang J, Wolf RM, Wu X, York DM, Kollman PA (2014) AMBER 14. University of California, San Francisco

38. Maier JA, Martinez C, Kasavajhala K, Wickstrom L, Hauser KE, Simmerling C (2015) J Chem Theory Comput 11:3696-3713

39. Jorgensen WL, Chandrasekhar J, Madura JD, Impey RW, Klein ML (1983) J Chem Phys 79:926-935

40. TURBOMOLE V7.1 2016, a development of University of Karlsruhe and Forschungszentrum Karlsruhe GmbH, 1989-2007, TURBOMOLE GmbH, since 2007; available from http://www. turbomole.com. Accessed 06 Oct 2016

41. Tao J, Perdew JP, Staroverov VN, Scuseria GE (2003) Phys Rev Lett 91:146401

42. Becke AD (1993) J Chem Phys 98:5648-5652

43. Becke AD (1988) Phys Rev A 38:3098-3100

44. Lee CT, Yang WT, Parr RG (1988) Phys Rev B 37:785-789

45. Schäfer A, Horn H, Ahlrichs R (1992) J Chem Phys 97:2571-2577

46. Weigend F, Ahlrichs R (2005) Phys Chem Chem Phys 7:3297-3305

47. Eichkorn K, Weigend F, Treutler O, Ahlrichs R (1997) Theor Chem Acc 97:119-124

48. Eichkorn K, Treutler O, Öhm H, Häser M, Ahlrichs R (1995) Chem Phys Lett 240:283-290

49. Szilagyi RK, Winslow MA (2006) J Comput Chem 27:1385-1397

50. Greco C, Fantucci P, Ryde U, De Gioia L (2011) Int J Quantum Chem 111:3949-3960

51. Ryde U, Olsson MHM (2001) Int J Quantum Chem 81:335-347

52. Ryde U (1996) J Comput Aided Mol Des 10:153-164

53. Reuter N, Dejaegere A, Maigret B, Karplus M (2000) J Phys Chem A 104:1720-1735

54. Hu L, Söderhjelm P, Ryde U (2011) J Chem Theory Comput 7:761-777

55. Svensson M, Humbel S, Froese RDJ, Matsubara T, Sieber S, Morokuma K (1996) J Phys Chem 100:19357-19363

56. dftd3 software https://www.chemie.uni-bonn.de/pctc/mullikencenter/software/dft-d3/dft-d3. Accessed 06 Oct 2016

57. Lanz ND, Lee KH, Horstmann AK, Pandelia ME, Cicchillo RM, Krebs C, Booker SJ (2016) Biochemistry 55:1372-1383 